\title{
BMJ Open Knowledge translation strategies for policy and action focused on sexual, reproductive, maternal, newborn, child and adolescent health and well-being: a rapid scoping review
}

Janet A Curran (D) , ${ }^{1,2}$ Allyson J Gallant (D) , ${ }^{3}$ Helen Wong, ${ }^{3}$ Hwayeon Danielle Shin, ${ }^{1}$ Robin Urquhart, ${ }^{4}$ Julia Kontak (D) , ${ }^{5}$ Lori Wozney, ${ }^{6}$ Leah Boulos, ${ }^{5}$ Zulfiqar Bhutta (1) , ${ }^{7}$ Etienne V Langlois ${ }^{8}$

To cite: Curran JA, Gallant AJ, Wong $\mathrm{H}$, et al. Knowledge translation strategies for policy and action focused on sexual, reproductive, maternal, newborn, child and adolescent health and well-being: a rapid scoping review. BMJ Open 2022;12:e053919. doi:10.1136/ bmjopen-2021-053919

- Prepublication history and additional supplemental material for this paper are available online. To view these files, please visit the journal online (http://dx.doi.org/10.1136/ bmjopen-2021-053919).

Received 30 May 2021 Accepted 16 December 2021

Check for updates

(C) Author(s) (or their employer(s)) 2022. Re-use permitted under CC BY. Published by BMJ.

For numbered affiliations see end of article.

Correspondence to Dr Janet A Curran; jacurran@dal.ca

\section{ABSTRACT}

Objective The aim of this study was to identify knowledge translation (KT) strategies aimed at improving sexual, reproductive, maternal, newborn, child and adolescent health (SRMNCAH) and well-being.

Design Rapid scoping review.

Search strategy A comprehensive and peer-reviewed search strategy was developed and applied to four electronic databases: MEDLINE ALL, Embase, CINAHL and Web of Science. Additional searches of grey literature were conducted to identify KT strategies aimed at supporting SRMNCAH. KT strategies and policies published in English from January 2000 to May 2020 onwards were eligible for inclusion.

Results Only $4 \%$ of included 90 studies were conducted in low-income countries with the majority $(52 \%)$ conducted in high-income countries. Studies primarily focused on maternal newborn or child health and wellbeing. Education (81\%), including staff workshops and education modules, was the most commonly identified intervention component from the KT interventions. Lowincome and middle-income countries were more likely to include civil society organisations, government and policymakers as stakeholders compared with high-income countries. Reported barriers to KT strategies included limited resources and time constraints, while enablers included stakeholder involvement throughout the KT process.

Conclusion We identified a number of gaps among KT strategies for SRMNCAH policy and action, including limited focus on adolescent, sexual and reproductive health and rights and SRMNCAH financing strategies. There is a need to support stakeholder engagement in $\mathrm{KT}$ interventions across the continuum of SRMNCAH services. Researchers and policymakers should consider enhancing efforts to work with multisectoral stakeholders to implement future KT strategies and policies to address SRMNCAH priorities.

Registration The rapid scoping review protocol was registered on Open Science Framework on 16 June 2020 (https://osf.io/xpf2k).

\section{Strengths and limitations of this study}

- Our review identified a broad range of knowledge translation (KT) strategies and policies aimed at improving sexual, reproductive, maternal, newborn, child and adolescent health and well-being published since January 2020.

- KT strategies and policies were mapped to the Behaviour Change Wheel to identify and describe intervention and policy elements included in the strategies.

- The terminology around KT varies across countries and health areas.

- As a rapid scoping review, full text and grey literature review and data extraction were carried out by a single reviewer and verified by a second reviewer.

- Although we conducted a systematic search of the grey literature it is possible our findings were impacted by our strict inclusion criteria and potential publication bias

\section{INTRODUCTION}

Progress towards sexual, reproductive, maternal, newborn, child and adolescent health (SRMNCAH) has been highly inequitable to date. ${ }^{12}$ With the current COVID-19 pandemic, there have been substantive and unprecedented disruptions in essential SRMNCAH services, ${ }^{3}$ including emerging data on increased maternal mortality, stillbirth rates, ruptured ectopic pregnancies, unintended pregnancies, maternal depression and limited access to contraceptives. ${ }^{45}$ The greatest disruptions to essential healthcare services are witnessed in low-income countries. $^{6}$ As such, special efforts are needed to support evidence-based interventions to prevent further harm, reduce 
preventable deaths and morbidity, and promote equitable distribution of essential interventions for SRMNCAH.

There is a lack of equitable distribution of human resources and essential policy adoptions for SRMNCAH in most countries. ${ }^{7}$ COVID-19 has also brought to the forefront the need to develop and implement multisectoral interventions using a whole-of-government approach. ${ }^{8}$ Improving SRMNCAH across countries of different income levels will require collective action in terms of generating, sharing, brokering and implementing new knowledge through cross-sectoral and interdisciplinary initiatives. ${ }^{9}$ The Partnership for Maternal, Newborn and Child Health (PMNCH), hosted by the WHO, is a global partnership designed to address these SRMNCAH inequities, and improve the health and well-being of all women, children and adolescents. ${ }^{10}$

Interventions shown to be effective by scientific endeavours require efforts to integrate evidence into policy and action. Knowledge translation (KT) is 'a dynamic and iterative process that includes synthesis, dissemination, exchange and ethically sound application of knowledge to improve the health, provide more effective health services and products and strengthen the healthcare system'. ${ }^{11}$ KT interventions can support this process by facilitating the uptake of evidence into policy and practice targeting change at the professional, institutional or policy level. There has been a growing number of KT interventions, as well as frameworks, theories and models to guide the selection of KT interventions. ${ }^{12-14}$ However, the range of KT strategies related to SRMNCAH improvements remains unknown.

No review to date has explored the range of KT interventions utilised at the level of health system, policy or practice specifically addressing the continuum of SRMNCAH. In light of the global call for action to sustain SRMNCAH, it is critical to understand the implementation of KT strategies that promote evidence-based policy and practice for SRMNCAH.

\section{Objectives}

The aim of this rapid scoping review was to identify existing literature related to KT strategies that promote the uptake of evidence into policy and action focused on improving SRMNCAH and well-being. To achieve this aim, four questions were addressed:

1. What are the common KT strategies and activities used to promote the use of evidence to inform policy and action to improve SRMNCAH and well-being?

2. How are stakeholders involved in designing or implementing these KT strategies and activities?

3 . What are the commonly reported outcomes of KT strategies and activities to promote the use of evidence in SRMNCAH and well-being?

4. What are the commonly reported barriers and enablers for using KT strategies and activities to promote the use of evidence in SRMNCAH and well-being?

\section{METHODS}

This rapid scoping review follows the methodological guidance developed by the Joanna Briggs Institute and is reported according to the Preferred Reporting Items for Systematic Reviews and Meta-Analyses-Extension for Scoping Reviews (PRISMA-ScR). ${ }^{15} 16$ The rapid scoping review protocol was registered on Open Science Framework on 16 June 2020 (https://osf.io/xpf2k).

\section{Inclusion and exclusion criteria}

All study designs were eligible for inclusion in the review. Studies were excluded if they focused on basic science or clinical management of women, newborn, child or adolescent aspects of health or well-being. Systematic reviews were also excluded; however, the reference lists of relevant reviews were examined to identify additional potential studies for inclusion. Studies published from 2000 onwards and published in English were eligible for inclusion.

Studies reporting a KT strategy aimed at supporting or improving health systems or policy decisions to support SRMNCAH and well-being were eligible for inclusion. KT strategies aimed at patients, caregivers, healthcare providers, healthcare management, health systems, policymakers, civil society organisations and funder or donors, within or outside the health sector, were also eligible as long as it was in the context of SRMNCAH and wellbeing. Studies that targeted these stakeholders outside of SRMNCAH and well-being were excluded. KT strategies addressing HIV were excluded, unless specifically focused on SRMNCAH. Study outcomes relating to the effectiveness or implementation of the KT strategy or activity and SRMNCAH were included. Studies that did not report primary outcomes relevant to KT or SRMNCAH were excluded.

\section{Search strategy and information sources}

A comprehensive search strategy was developed with support from an experienced library scientist. The search strategy was peer-reviewed by a second library scientist using the Peer Review of Electronic Search Strategy guidelines to ensure a comprehensive and high-quality search strategy was developed. ${ }^{17}$ An electronic database search of MEDLINE ALL (Ovid), Embase (Elsevier Embase.com), CINAHL with Full Text (EBSCOhost) and Web of Science (SCI-EXPANDED, SSCI, A\&HCI, CPCI-S, CPCI-SSH, ESCI; Clarivate) was executed on 29 May 2020, and results were limited from January 2000 to the search date (see online supplemental file 1). No search filters or other limits were applied. Search strategy citations were imported into Covidence, an online systematic review management software, and duplicates were removed automatically in Covidence prior to screening. ${ }^{18}$ Reference lists of all included studies, as well as those of any relevant systematic reviews, were screened by one reviewer and verified by a second. Additionally, a search of grey literature was undertaken by a reviewer in July 2020. Search terms were applied in Google and relevant 
website links were clicked through to identify any reports or literature. The reviewer clicked through each relevant website and used reference chaining within the website to ensure any and all relevant literature was identified. Google results were browsed until the reviewer went two pages (20 results) without clicking on a potentially relevant result. The website URL links were compiled and verified for inclusion by another team member.

\section{Selection of sources of evidence}

Reviewers independently screened titles and abstracts against the inclusion criteria, and all conflicts were resolved by a third reviewer. Full-text articles were then reviewed and assessed against the inclusion criteria by one reviewer then verified by the second reviewer. Uncertainties at this stage were resolved through discussions with the research team. The reference lists of included fulltext articles were then reviewed to identify other potential studies for inclusion.

\section{Data charting and data items}

Data were extracted and mapped to four categories: descriptive details of the study (eg, authors and year, country, sample characteristics, study design, decisionmaking level, and SRMNCAH priority), characteristics of the KT strategy or activity, (eg, description of individual components, mode of delivery, stakeholder involvement), outcomes and direction of effect, and barriers and enablers identified by study authors. Study data were extracted using the data extraction tool by one reviewer and was verified by another to ensure all relevant data were captured. Critical appraisal of individual sources of evidence were not conducted.

\section{Synthesis of results}

Following data extraction, the income level of each country identified from the studies was determined using the World Bank classification. ${ }^{19}$ Study details were grouped into four categories that aligned with each of the research questions: KT strategy, stakeholder engagement, reported outcomes and types of barriers and enablers identified. Quantitative summaries and thematic analysis were then applied to each grouping to identify potential trends across country income levels and SRMNCAH thematic areas. Study data were also mapped on to the PMNCH's high-level outcomes of interest identified in the 2021-2025 Strategy (eg, policy, service delivery, financing $)^{10}$ and narrative summaries were produced.

To facilitate summarising content associated with the KT strategies, details of each KT strategy were mapped to the Behaviour Change Wheel (BCW). ${ }^{20}$ The BCW provides a synthesis of 19 behaviour change theories in a comprehensive, theory-based tool that can be used to identify important behaviour change elements to consider in intervention design. ${ }^{21}$ The BCW includes nine intervention functions that can be used to guide intervention content and design. It also includes seven policy categories to guide implementation of behaviour change interventions and policies. ${ }^{20} \mathrm{KT}$ strategies were mapped to relevant BCW intervention functions and policy categories by two independent researchers. Researchers met to review BCW coding and discrepancies were resolved through discussion.

\section{Patient and public involvement}

This scoping review was conducted without the involvement of patients or members of the public.

\section{RESULTS}

\section{Selection of sources of evidence}

The search strategy returned 11190 studies for screening. After removing 3626 duplicates, 7564 titles and abstracts were screened by reviewers. This stage identified 212 full-text studies to review. Following full-text analysis, 154 studies were excluded, resulting in 58 studies included in the review. A review of the reference lists of included studies identified 26 additional studies that met the inclusion criteria. The grey literature search identified one study for inclusion; five additional studies were included from screening the reference list of a relevant systematic review. This resulted in a final total of 90 included studies in the scoping review. The selection process and sources of evidence are summarised in a PRISMA-ScR flow diagram (figure 1). ${ }^{22}$

\section{Characteristics of sources of evidence}

A summary of the characteristics of the 90 included studies can be found in table 1 , with a comprehensive description of studies found in online supplemental file 2. All studies were published between 2000 and 2020, with an increase in relevant publications since 2006. Just over a third (34\%) were published between 2011 and $2015^{23-53}$ and another $34 \%$ between 2016 and $2020 .{ }^{54-84}$ Thirty-two per cent of studies were quasi-experimental designs, ${ }^{23} 2526283132343544505159-61676875768385-92$ with observational (22\%), 36373943455271727780 93-102 mixed-methods $(17 \%),{ }^{40-42475356-58646982103-106}$ experimental $(16 \%)^{2427386266747879107-112}$ and qualitative $(11 \%)^{29} 3033495455637081113$ designs also identified. Two editorials were also included. ${ }^{6573}$

\section{Country income levels}

The majority of the studies (52\%) were conducted in high-income countries, ${ }^{23-25}$ 27-29 31 33-35 384041 43-45 4953565762 66-6871 7374 7480838793-959798100 102-105107108108109112 including Canada, the USA and Australia. Middle-income countries were the setting for 36\% studies, ${ }^{26} 303236394246-48505263-65$ 75-77 81828586 88-9296101 110111113 including Nepal, Egypt and Zambia, with most middle-income countries considered low-middle income $(81 \%)$ and $19 \%$ considered uppermiddle income. Only $4 \%$ of included studies were located in low-income countries, such as Uganda and Madagascar. ${ }^{58-6099}$ Seven countries (ie, Bangladesh, Cameroon, Ethiopia, Myanmar, Nigeria, Solomon Islands and Uganda) across $14 \%$ of studies represented humanitarian or highly fragile settings, ${ }^{3742} 5458596170728599$ according 


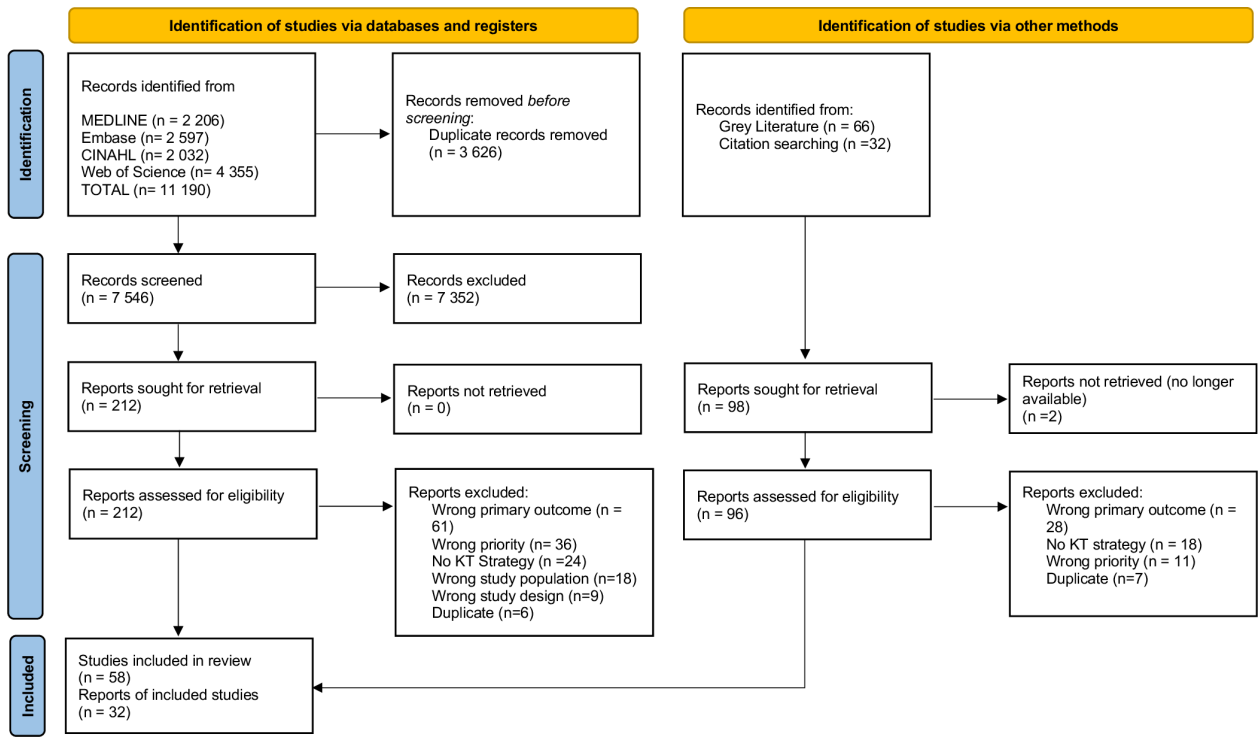

Figure 1 Preferred Reporting Items for Systematic Reviews and Meta-Analyses-Extension for Scoping Reviews flow diagram of literature search. KT, knowledge translation.

to Organisation for Economic Co-operation and Development. ${ }^{114}$ Eight per cent of studies included multi-income countries, with six targeting both low-income and middleincome countries (eg, Uganda and Peru), ${ }^{375461697072}$ and one targeting middle-income and high-income countries (eg, Brazil and Chile). ${ }^{106}$ As results were reported by country in these seven studies, we analysed these studies at each of the appropriate income levels.

\section{SRMNCAH priorities}

Child health and well-being was the most commonly identified priority, with 30\% targeting these concerns. ${ }^{27} 293233$

Table 1 Overview of characteristics of included studies $(n=90)$

\begin{tabular}{|c|c|c|c|c|c|c|}
\hline $\begin{array}{l}\text { Publication } \\
\text { date }\end{array}$ & $\begin{array}{l}\text { Country } \\
\text { by income } \\
\text { level }\end{array}$ & Study design & $\begin{array}{l}\text { SRMNCAH } \\
\text { priorities }\end{array}$ & $\begin{array}{l}\text { Examples of } \\
\text { SRMNCAH health } \\
\text { topics }\end{array}$ & Settings & $\begin{array}{l}\text { PMNCH function } \\
\text { of interest }\end{array}$ \\
\hline $\begin{array}{l}\text { 2000-2005: } \\
n=8 \text { (9\%) } \\
\text { 2006-2010: } \\
n=20(22 \%) \\
2011-2015: \\
n=31(34 \%) \\
2016-2020: \\
n=31(34 \%)\end{array}$ & $\begin{array}{l}\text { Low: } \mathrm{n}=4 \\
\text { (4\%) } \\
\text { Low and } \\
\text { middle: } \\
\mathrm{n}=6(7 \%) \\
\text { Lower } \\
\text { middle: } \\
\mathrm{n}=26 \\
(81 \%) \\
\text { Upper } \\
\text { middle: } \\
\mathrm{n}=6(19 \%) \\
\text { Middle } \\
\text { and High: } \\
\mathrm{n}=1(1 \%) \\
\text { High: } \mathrm{n}=47 \\
(52 \%)\end{array}$ & $\begin{array}{l}\text { Experimental: } n=14 \\
(16 \%) \\
\text { Quasi-experimental: } \\
n=29(32 \%) \\
\text { Observational: } n=20 \\
(22 \%) \\
\text { Qualitative: } n=10(11 \%) \\
\text { Mixed methods: } n=15 \\
\text { (17\%) } \\
\text { Editorials: } n=2(2 \%)\end{array}$ & $\begin{array}{l}\text { Adolescent: } \\
\mathrm{n}=4(4 \%) \\
\text { Child: } \mathrm{n}=28 \\
(31 \%) \\
\text { Maternal: } \\
\mathrm{n}=14(16 \%) \\
\text { Newborn or } \\
\text { stillbirths: } \\
\mathrm{n}=20(22 \%) \\
\text { Maternal } \\
\text { and } \\
\text { newborn: } \\
\mathrm{n}=8(9 \%) \\
\text { Maternal } \\
\text { and child: } \\
\mathrm{n}=2(2 \%) \\
\text { Maternal } \\
\text { and child } \\
\text { and } \\
\text { newborn: } \\
\mathrm{n}=2(2 \%) \\
\text { SRHR: } n=12 \\
(13 \%)\end{array}$ & $\begin{array}{l}\text { Adolescent: } \\
\text { substance use }{ }^{107} \\
\text { Child: } \\
\text { Child nutrition }{ }^{27} 3538 \\
67747879 \\
\text { Maternal: } \\
\text { postpartum } \\
\text { depression, }^{45} \\
\text { eclampsia and pre- } \\
\text { eclampsia }^{113} \\
\text { Newborn or } \\
\text { stillbirths: } \\
\text { Newborn } \\
\text { sleep, }{ }^{23} \text { newborn } \\
\text { vaccination } \\
\text { SRHR: } \\
\text { Family planning } \\
656970101\end{array}$ & $\begin{array}{l}\text { Hospitals: } n=35 \\
\text { (39\%) } \\
\text { Community: } \\
n=23(25 \%) \\
\text { Childcare } \\
\text { centres or } \\
\text { schools: } n=10 \\
(11 \%) \\
\text { Primary Care: } \\
n=7(8 \%) \\
\text { Government } \\
\text { departments: } \\
n=3(3 \%)\end{array}$ & $\begin{array}{l}\text { Financing: } n=0 \\
\text { Policymaking: } \\
n=17(19 \%) \\
\text { Service delivery: } \\
n=73(81 \%)\end{array}$ \\
\hline
\end{tabular}

PMNCH, Partnership for Maternal, Newborn and Child Health; SRHR, sexual and reproductive health and rights; SRMNCAH, sexual, reproductive, maternal, newborn, child and adolescent health. 
$35363840434647515762677478-80838589919498-100105108110$ Twentyeight per cent addressed newborn health and well-being or stillbirths, $232526283134505960606468818286889095-97109111$ and a quarter of studies addressed maternal health and well-being. $^{24} 373944455254555863727375-77879293103104112113$ Studies addressing sexual and reproductive health and rights (SRHR (12\%)) $30384261656669-71101106$ and adolescent health and well-being (4\%) 334156107 priorities were identified, but in a lower volume compared with studies addressing maternal, child and newborn or stillbirth priorities. Some studies (13\%) also included multiple SRMNCAH priorities, with eight targeting both maternal and newborn health and well-being, targeting maternal and child health and well-being ${ }^{52} 72$ and two targeting maternal, child and newborn health and well-being. ${ }^{7576}$ These studies were analysed at each of the appropriate priority levels.

\section{PMNCH high-level Outcomes (2021-2025)}

Across the priority high-level outcomes of the PMNCH 2021-2025 Strategy, the majority of included studies $(81 \%)$ addressed service delivery. Policymaking was also commonly identified (19\%). None of the included KT strategies addressed financing as a central focus.

\section{Settings}

KT strategies were primarily implemented in hospitals $(39 \%)$, community $(25 \%)$ or primary care $(8 \%)$ settings. Three per cent of strategies were conducted within government health departments or agencies. ${ }^{7173108}$ There were rarely enough details provided to explore specific departmental settings in hospitals, although four hospital studies were conducted in newborn and paediatric intensive care units, ${ }^{26} 3189109$ one in a labour and delivery department ${ }^{93}$ and one specified the hospital was in a rural setting. ${ }^{86}$ Community settings were also described in limited detail; however, eight studies were conducted in childcare centres, ${ }^{2735386267747983}$ two in schools ${ }^{78107}$ and one in a mental health community clinic. ${ }^{56}$

\section{Synthesis of KT strategies and activities}

\section{BCW intervention functions}

Mapping the KT strategies to the BCW intervention functions identified that all but one study contained at least one intervention function. All nine BCW intervention functions were identified across the KT strategies, with Education, Training and Environmental Restructuring the most common (table 2 ).

Education was the most commonly identified element from the included studies, identified in $81 \%$ of studies. Types of Education provided included modules, staff workshops, slides and other resources. This function was identified in $73 \mathrm{KT}$ strategies across country income levels $(88 \%$ in high-income countries, $80 \%$ of low-income countries and $77 \%$ of middle-income countries). At the SRMNCAH priority level, 91\% of child health and wellbeing strategy included an Education function. Education was also identified in $81 \%$ of the maternal health interventions, as well as $75 \%$ of each of the SRHR, and adolescent and well-being interventions.

Training was identified in $51 \%$ of strategies. Training typically included conveying skills to staff members and healthcare providers. This element was included in $60 \%$ of the KT strategies aimed at low-income countries, $52 \%$ of high-income countries and $41 \%$ of middle-income countries. Strategies stratified by SRMNCAH priority identified Training was utilised consistently across each priority.

Environmental Restructuring was identified in 50\% of the KT strategies. This element included reorganising how services were provided, how health centres were set up and adding additional resources (eg, tools, team members) in the health centre or health system to facilitate use of the KT strategy. This element was identified at all three income levels but was more likely to be used in high-income countries (58\%), compared with middle $(41 \%)$ and low-income $(40 \%)$ countries. Sixty-nine per cent of child health and well-being strategies included this function, as well as $50 \%$ of the SRHR strategies. Environmental Restructuring was only applied in one $(25 \%)$ of the four adolescent health and well-being strategies.

\section{BCW policy categories}

Sixty per cent of studies included policy category content, with six of the seven BCW policy categories were identified across the strategies (table 2). No strategies applied content related to the Fiscal category option. Guidelines and Service Provision were the most commonly identified, with Guidelines identified in 28\% of KT strategies and Service Provision identified in $20 \%$ of studies. Guidelines were implemented in $50 \%$ of the low-income countries, compared with only $31 \%$ of middle-income and $25 \%$ of the high-income countries. Guidelines were most frequently used in $50 \%$ of KT strategies related to sexual or reproductive health and rights, and $36 \%$ of maternal health and well-being strategies.

Service Provision was implemented in $89 \%$ of the highincome countries, compared with only $5 \%$ of middleincome countries and none of the low-income countries. This policy category was divided across SRMNCAH priorities. SRHR included Service Provision in 25\% of strategies, and $25 \%$ of strategies targeting adolescent health and well-being included this category.

\section{Mode of KT delivery}

Seventy-two per cent of KT strategies identified the mode of KT delivery, with the majority using one mode of delivery, while $27 \%$ used two or more modes. The majority $(59 \%)$ of these studies used in-person delivery as the sole mode of delivery. Of the multimodal delivery strategies, in-person delivery was also included as a mode in all but one study. ${ }^{111}$ High-income countries used more multimode interventions, such as in-person with additional online or web-based components, compared with those in low-income and middle-income countries. Studies published between 2018 and 2020 have used 
Table 2 Summary of BCW intervention functions and policy categories identified in KT strategies by country income level and SRMNCAH priority

\section{BCW intervention functions}

\begin{tabular}{|c|c|c|}
\hline Intervention function and definition ${ }^{20}$ & $\begin{array}{l}\text { Intervention function stratified by } \\
\text { country income level* }\end{array}$ & $\begin{array}{l}\text { Intervention function stratified by } \\
\text { SRMNCAH priority† }\end{array}$ \\
\hline $\begin{array}{l}\text { Education (n=73; } 81 \% \text { ) } \\
\text { (Increasing knowledge or understanding) }\end{array}$ & $\begin{array}{l}\text { Low: } n=8(80 \%) \\
\text { Middle: } n=30(77 \%) \\
\text { High: } n=45(88 \%)\end{array}$ & $\begin{array}{l}\text { Adolescent: } n=3(75 \%) \\
\text { Child: } n=29(91 \%) \\
\text { Maternal: } n=21(78 \%) \\
\text { Newborn or stillbirths: } n=23(77 \%) \\
\text { SRHR: } n=9(75 \%)\end{array}$ \\
\hline $\begin{array}{l}\text { Environmental restructuring ( } \mathrm{n}=45 ; 50 \%) \\
\text { (changing the physical or social context) }\end{array}$ & $\begin{array}{l}\text { Low: } n=4(40 \%) \\
\text { Middle: } n=16(41 \%) \\
\text { High: } n=30(58 \%)\end{array}$ & $\begin{array}{l}\text { Adolescent: } n=1(25 \%) \\
\text { Child: } n=22(69 \%) \\
\text { Maternal: } n=10(38 \%) \\
\text { Newborn or stillbirths: } n=14(47 \%) \\
\text { SRHR: } n=6(50 \%)\end{array}$ \\
\hline $\begin{array}{l}\text { Persuasion ( } n=11 ; 12 \%) \text { (communication } \\
\text { used to induce positive or negative feelings } \\
\text { or stimulate action) }\end{array}$ & $\begin{array}{l}\text { Low: } n=1(10 \%) \\
\text { Middle: } n=2(5 \%) \\
\text { High: } n=10(21 \%)\end{array}$ & $\begin{array}{l}\text { Adolescent: } n=0 \\
\text { Child: } n=8(25 \%) \\
\text { Maternal: } n=3(12 \%) \\
\text { Newborn or stillbirths: } n=1(3 \%) \\
\text { SRHR: } n=1(8 \%)\end{array}$ \\
\hline $\begin{array}{l}\text { Modelling }(\mathbf{n}=\mathbf{7} ; \mathbf{8} \%) \\
\text { (providing an example for people to aspire } \\
\text { to or imitate) }\end{array}$ & $\begin{array}{l}\text { Low: } n=0 \\
\text { Middle: } n=3(8 \%) \\
\text { High: } n=4(8 \%)\end{array}$ & $\begin{array}{l}\text { Adolescent: } n=0 \\
\text { Child: } n=2(6 \%) \\
\text { Maternal: } n=2(8 \%) \\
\text { Newborn or stillbirths: } n=2(7 \%) \\
\text { SRHR: } n=1(8 \%)\end{array}$ \\
\hline $\begin{array}{l}\text { Coercion }(\mathbf{n}=2 ; \mathbf{2} \%) \\
\text { (creating expectation of punishment or cost) }\end{array}$ & $\begin{array}{l}\text { Low: } n=1(10 \%) \\
\text { Middle: } n=1(3 \%) \\
\text { High: } n=0\end{array}$ & $\begin{array}{l}\text { Adolescent: } n=0 \\
\text { Child: } n=0 \\
\text { Maternal: } n=1(4 \%) \\
\text { Newborn or stillbirths: } n=2(7 \%) \\
\text { SRHR: } n=0\end{array}$ \\
\hline $\begin{array}{l}\text { Restriction ( } n=1 ; 1 \%) \text { (using rules to } \\
\text { reduce the opportunity to engage in the } \\
\text { target behaviour) }\end{array}$ & $\begin{array}{l}\text { Low: } n=0 \\
\text { Middle: } n=1(3 \%) \\
\text { High: } n=0\end{array}$ & $\begin{array}{l}\text { Adolescent: } n=0 \\
\text { Child: } n=0 \\
\text { Maternal: } n=0 \\
\text { Newborn or stillbirths: } n=1(3 \%) \\
\text { SRHR: } n=0\end{array}$ \\
\hline
\end{tabular}

\section{BCW policy categories}

$\begin{array}{lll}\text { Policy category and definition }{ }^{20} & \begin{array}{l}\text { Policy category stratified by } \\ \text { country income level }\end{array} & \begin{array}{l}\text { Policy category stratified by SRMNCAH } \\ \text { priority }\end{array} \\ \begin{array}{l}\text { Guidelines }(\mathbf{n}=\mathbf{2 5} ; \mathbf{2 8} \%) \\ \text { (creating documents that recommend or }\end{array} & \begin{array}{l}\text { Low: } n=5(50 \%) \\ \text { Middle: } n=12(31 \%)\end{array} & \begin{array}{l}\text { Adolescent: } n=1(25 \%) \\ \text { Child: } n=6(19 \%)\end{array} \\ \text { mandate practice) } & \text { High: } n=12(25 \%) & \text { Maternal: } n=9(35 \%) \\ & & \text { Newborn or stillbirths: } n=8(27 \%) \\ & & \text { SRHR: } n=5(42 \%)\end{array}$


Table 2 Continued

BCW intervention functions

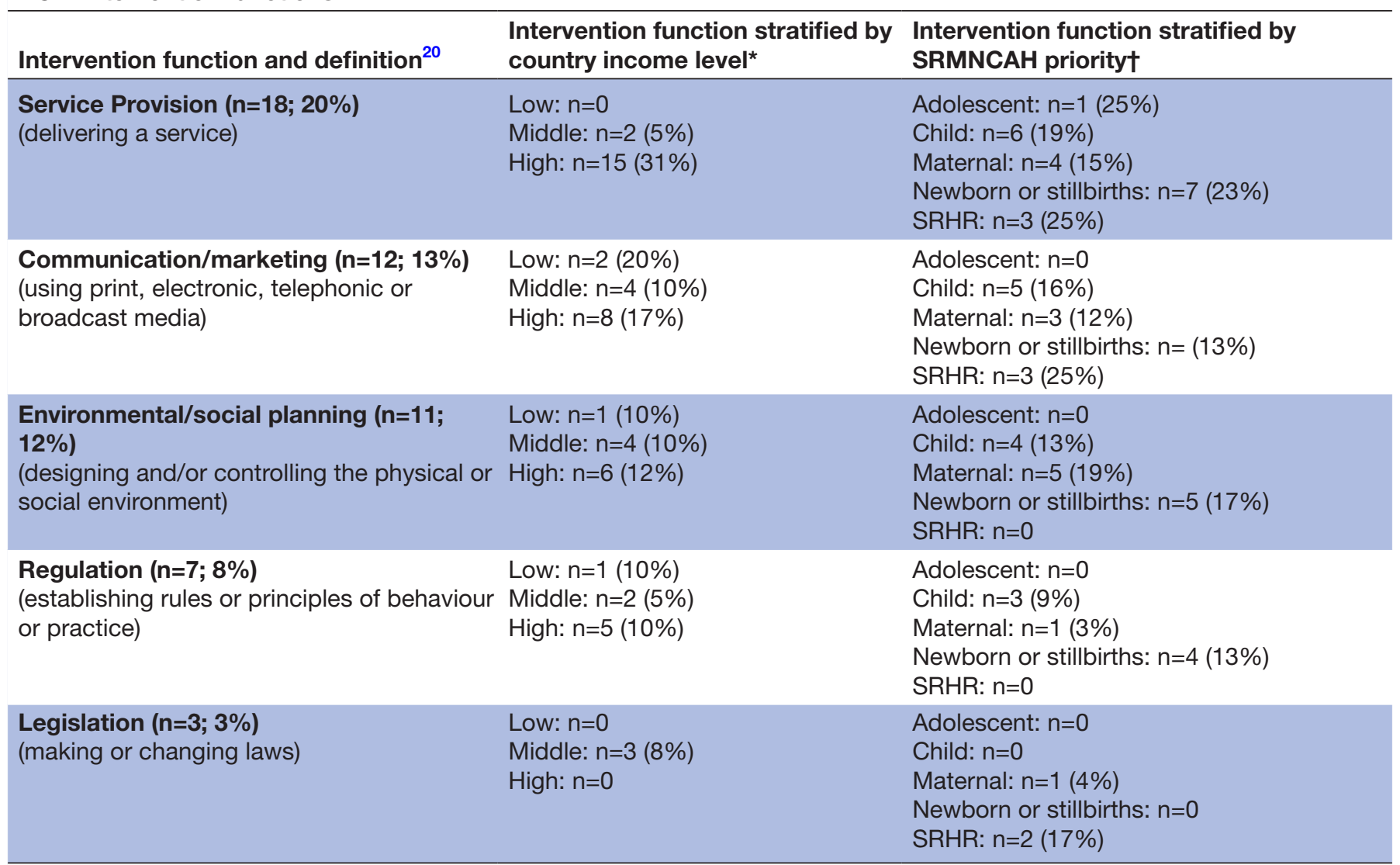

*Please note country income levels include seven multicountry studies $(n=97)$.

†Please note priorities include 12 multipriority studies $(n=104)$.

$\mathrm{BCW}$, Behaviour Change Wheel; SRHR, sexual and reproductive health and rights.

evolving trends in technology, such as webinars and social media, ${ }^{73} 83$ as modes of delivery.

\section{Synthesis of stakeholder involvement}

There was an overall lack of description provided on how stakeholders were involved in designing or implementing KT strategies, with $31 \%$ of studies not providing any description of stakeholder engagement. Of the remaining studies that did provide details, the level of detail varied by article, with some simply acknowledging stakeholders were engaged, while others provided a more comprehensive view of the stakeholder groups involved and their roles. Commonly identified stakeholder groups included: government and policymakers, healthcare providers, civil society organisations, members of the public and members of the research community (table 3). Engagement with these groups was distributed across country income level, with two notable exceptions. First, civil society organisations were more likely to be engaged in low $(60 \%)$ and middle-income $(48 \%)$ countries compared with high-income $(27 \%)$ countries. Additionally, government and policymakers were engaged by low $(50 \%)$ and middle-income $(62 \%)$ countries much more often than in high-income $(8 \%)$ countries.
Stakeholder engagement was dispersed across the SRMNCAH priorities. Priorities addressing SRHR were more likely to include policymakers and government as well as civil society organisations compared with other priorities. Half of strategies addressing adolescent health and well-being, while $25 \%$ of SRHR engaged healthcare providers including clinicians, nurses and allied healthcare professionals. Involvement of researcher communities was identified across all six priorities but was rarely used in newborn health and well-being or stillbirth strategies $(7 \%)$.

\section{Synthesis of outcomes}

Nearly $80 \%$ of KT strategy outcomes were reported at only a single outcome level (eg, patient or healthcare provider), with $20 \%$ studies reporting multiple outcome levels (eg, healthcare provider and system). At the single outcome level, $38 \%$ of outcomes were measured at the healthcare provider level (eg, increased knowledge) and $29 \%$ at system level (eg, reductions in safety incidents). Only $5 \%$ of strategies included patient-level outcomes (eg, improved newborn sleep). Patient outcomes were more likely to be included in multilevel outcomes, along with healthcare provider and system level (eg, immunisation 


\section{Table 3 Summary of stakeholder engagement by country income level and SRMNCAH priority}

\section{Type of}

\section{stakeholders}

involved in KT

strategy

\begin{tabular}{ll}
\hline Policymakers and & Low: $n=5(50 \%)$ \\
government & Middle: $n=24$ \\
& (62\%) \\
& High: $n=4(8 \%)$
\end{tabular}

Stakeholders by country income level*

\section{Stakeholders by} SRMNCAH priority†

Adolescent: $n=1$ (25\%) Child: $n=4(13 \%)$

Maternal: $n=9$ (35\%) Newborn or stillbirths: $n=3(10 \%)$ SRHR: $n=7(63 \%)$

\section{Healthcare} providers and administrators

Low: $\mathrm{n}=5$ (50\%)

Middle: $\mathrm{n}=17$ (44\%)

Adolescent: $\mathrm{n}=2$

(50\%)

Child: $n=10(31 \%)$

High: $n=23$ (48\%) Maternal: $n=11(42 \%)$

Newborn or stillbirths: $n=9(30 \%)$ SRHR: $n=3$ (25\%)

\begin{tabular}{|c|c|c|}
\hline $\begin{array}{l}\text { Civil society } \\
\text { organisations }\end{array}$ & $\begin{array}{l}\text { Low: } n=6(60 \%) \\
\text { Middle: } n=19 \\
\text { (48\%) } \\
\text { High: } n=13(27 \%)\end{array}$ & $\begin{array}{l}\text { Adolescent: } n=1 \\
\text { (25\%) } \\
\text { Child: } n=4(13 \%) \\
\text { Maternal: } n=3(13 \%) \\
\text { Newborn or } \\
\text { stillbirths: } n=2(7 \%) \\
\text { SRHR: } n=7(63 \%)\end{array}$ \\
\hline Public & $\begin{array}{l}\text { Low: } n=2(20 \%) \\
\text { Middle: } n=1(3 \%) \\
\text { High: } n=10(21 \%)\end{array}$ & $\begin{array}{l}\text { Adolescent: } n=2 \\
\text { (50\%) } \\
\text { Child: } n=3(9 \%) \\
\text { Maternal: } n=1(4 \%) \\
\text { Newborn or } \\
\text { stillbirths: } n=2(7 \%) \\
\text { SRHR: } n=2(17 \%)\end{array}$ \\
\hline $\begin{array}{l}\text { Research } \\
\text { community }\end{array}$ & $\begin{array}{l}\text { Low: } n=3(30 \%) \\
\text { Middle: } n=10 \\
\text { (26\%) } \\
\text { High: } n=17(35 \%)\end{array}$ & $\begin{array}{l}\text { Adolescent: } n=1 \\
(25 \%) \\
\text { Child: } n=9(28 \%) \\
\text { Maternal: } n=10(38 \%) \\
\text { Newborn or } \\
\text { stillbirths: } n=2(7 \%) \\
\text { SRHR: } n=3(25 \%)\end{array}$ \\
\hline
\end{tabular}

*Please note country income levels include seven multicountry studies $(n=97)$.

†Please note priorities include 12 multipriority studies $(n=104)$. $\mathrm{KT}$, knowledge translation; SRHR, sexual and reproductive health and rights; SRMNCAH, sexual, reproductive, maternal, newborn, child and adolescent health.

rates, quality of care provided and healthcare system use) outcomes. Of the multilevel outcome studies, $17 \%$ had outcomes at two levels (eg, patient and healthcare providers, healthcare providers and system or patient and system) and $4 \%$ of studies included three-level outcomes (eg, patient, healthcare provider and system).

Healthcare provider outcomes were mostly reported in high-income $(44 \%)$ and low-income $(40 \%)$ countries, compared with $26 \%$ of middle-income countries, while system-level outcomes were more common in low-income $(40 \%)$ and middle-income (41\%) countries. Healthcare provider outcomes were identified across the SRMNCAH priorities, ranging from $23 \%$ to $75 \%$ for maternal health and well-being strategies to those for adolescent wellbeing, respectively. While fewer maternal health and well-being strategies included healthcare provider-level outcomes, nearly half of these strategies $(48 \%)$ were aimed at system-level outcomes. Childhood health and well-being strategies were also most likely to address multi-level outcomes compared with all other priorities.

\section{Synthesis of barriers and enablers}

Few studies reported barriers and enablers to using KT strategies to promote the use of evidence in SRMNCAH and well-being. Fewer than half of the studies (43\%) outlined barriers and even fewer identified enablers $(40 \%)$ to their KT strategies. When studies included barriers and enablers, the level of detail provided varied across the studies, with some studies providing a brief list of these factors while other studies provided more detailed descriptions and how each affected the KT strategy. A summary of identified barriers and enablers can be found in table 4 .

\section{Identified barriers}

Limited resources was the most commonly reported barrier for using KT strategies across countries of all income levels and SRMNCAH priorities. In $56 \%$ of strategies, limited resources referred to physical (eg, funding) or human resources (eg, healthcare staff) constraints. Low-income countries were more likely to report limited resources $(40 \%)$ compared with high-income countries (19\%). In terms of SRMNCAH priority, $50 \%$ of SRHR strategies identified limited resources as barriers to using KT strategies.

Second, time constraints were reported in $21 \%$ of high-income countries. This type of barrier delayed the implementation process, including fidelity of KT strategies. Lastly, negative attitudes were the third commonly reported barrier, reported by $30 \%$ of low-income countries. Examples of negative attitudes included resistance to change, lack of confidence and poor 'buy-in' for using KT strategies.

\section{Identified Enablers}

Supportive stakeholder involvement was the most commonly identified enabler to KT strategies. Two-thirds of studies which reported enablers identified the importance of developing supportive relationships with stakeholders, and that the partnerships forged supported the implementation of the KT strategy. Supportive stakeholder involvement included successful collaboration and partnerships with, but not limited to, healthcare providers, government bodies or non-profit organisations. This enabler was identified across all country income levels but was most common in low-income countries (40\%). In terms of SRMNCAH priority, 67\% of SRHR studies reported supportive stakeholder involvement as enablers. 
Table 4 Summary of barriers and enablers identified across strategies by country income level and SRMNCAH priority

Barriers identified across studies $(n=39)$

\begin{tabular}{|c|c|c|}
\hline & Stratified by country income level ${ }^{*}$ & Stratified by SRMNCAH priority† \\
\hline $\begin{array}{l}\text { Time constraints } \\
(n=12)\end{array}$ & $\begin{array}{l}\text { Low: } n=0 \\
\text { Middle: } n=2(5 \%) \\
\text { High: } n=10(21 \%)\end{array}$ & $\begin{array}{l}\text { Adolescent: } n=1(25 \%) \\
\text { Child: } n=5(16 \%) \\
\text { Maternal: } n=2(8 \%) \\
\text { Newborn or stillbirths: } n=2(7 \%) \\
\text { SRHR: } n=2(13 \%)\end{array}$ \\
\hline $\begin{array}{l}\text { Negative attitudes } \\
(n=10)\end{array}$ & $\begin{array}{l}\text { Low: } n=3(30 \%) \\
\text { Middle: } n=3(8 \%) \\
\text { High: } n=5(10 \%)\end{array}$ & $\begin{array}{l}\text { Adolescent: } n=1(25 \%) \\
\text { Child: } n=2(6 \%) \\
\text { Maternal: } n=3(12 \%) \\
\text { Newborn or stillbirths: } n=1(3 \%) \\
\text { SRHR: } n=3(25 \%)\end{array}$ \\
\hline $\begin{array}{l}\text { Lack of training } \\
(n=7)\end{array}$ & $\begin{array}{l}\text { Low: } n=0 \\
\text { Middle: } n=0 \\
\text { High: } n=7(15 \%)\end{array}$ & $\begin{array}{l}\text { Adolescent: } n=1(25 \%) \\
\text { Child: } n=4(13 \%) \\
\text { Maternal: } n=2(8 \%) \\
\text { Newborn or stillbirths: } n=0 \\
\text { SRHR: } n=0\end{array}$ \\
\hline $\begin{array}{l}\text { Poor engagement with stakeholders } \\
(n=7)\end{array}$ & $\begin{array}{l}\text { Low: } n=0 \\
\text { Middle: } n=4 \\
\text { High: } n=3\end{array}$ & $\begin{array}{l}\text { Adolescent: } n=1(25 \%) \\
\text { Child: } n=3(9 \%) \\
\text { Maternal: } n=3(12 \%) \\
\text { Newborn or stillbirths: } n=1(3 \%) \\
\text { SRHR: } n=1(8 \%)\end{array}$ \\
\hline
\end{tabular}

\begin{tabular}{|c|c|c|}
\hline & Stratified Country Income Level* & Stratified by SRMNCAH Priority** \\
\hline $\begin{array}{l}\text { Supportive stakeholder involvement } \\
(\mathrm{n}=24)\end{array}$ & $\begin{array}{l}\text { Low: } n=4(40 \%) \\
\text { Middle: } n=10(26 \%) \\
\text { High: } n=10(21 \%)\end{array}$ & $\begin{array}{l}\text { Adolescent: } n=2(50 \%) \\
\text { Child: } n=3(9 \%) \\
\text { Maternal: } n=7(27 \%) \\
\text { Newborn or stillbirths: } n=4(13 \%) \\
\text { SRHR: } n=8(67 \%)\end{array}$ \\
\hline $\begin{array}{l}\text { Access to resources } \\
(n=8)\end{array}$ & $\begin{array}{l}\text { Low: } n=2(20 \%) \\
\text { Middle: } n=2(5 \%) \\
\text { High: } n=4(8 \%)\end{array}$ & $\begin{array}{l}\text { Adolescent: } n=0 \\
\text { Child: } n=1(3 \%) \\
\text { Maternal: } n=3(12 \%) \\
\text { Newborn or stillbirths: } n=3(10 \%) \\
\text { SRHR: } n=2(17 \%)\end{array}$ \\
\hline $\begin{array}{l}\text { Access to knowledge } \\
(\mathrm{n}=8)\end{array}$ & $\begin{array}{l}\text { Low: } n=4(40 \%) \\
\text { Middle: } n=4(10 \%) \\
\text { High: } n=0\end{array}$ & $\begin{array}{l}\text { Adolescent: } n=0 \\
\text { Child: } n=2(6 \%) \\
\text { Maternal: } n=3(12 \%) \\
\text { Newborn or stillbirths: } n=2(7 \%) \\
\text { SRHR: } n=3(25 \%)\end{array}$ \\
\hline
\end{tabular}


Table 4 Continued

Barriers identified across studies $(n=39)$

\begin{tabular}{lll}
\hline & Stratified by country income level & Stratified by SRMNCAH priority \\
\hline Skills and training & Low: $n=0$ & Adolescent: $n=0$ \\
$(n=6)$ & Middle: $n=0$ & Child: $n=3(9 \%)$ \\
& High: $n=6(13 \%)$ & Maternal: $n=2(8 \%)$ \\
& & Newborn or stillbirths: $n=0$ \\
& & SRHR: $n=1(8 \%)$ \\
\hline
\end{tabular}

*Please note country income levels include seven multicountry studies $(n=97)$.

†Please note priorities include 12 multipriority studies $(n=104)$.

SRHR, sexual and reproductive health and rights; SRMNCAH, sexual, reproductive, maternal, newborn, child and adolescent health.

Second, access to resources and knowledge was the next commonly reported enablers for using KT strategies. Resources in these articles included financial as well as human resources. This enabler was more common in lowincome countries (20\%) compared with middle-income $(8 \%)$ or high-income $(5 \%)$ countries. This enabler was identified across the SRMNCAH priorities, with the exception of adolescents' health and well-being. Finally, only high-income countries reported skills and training as enablers for using KT strategies.

\section{DISCUSSION}

This rapid scoping review identified 90 studies published since 2000 which utilised KT strategies and policies to support the use of evidence for improving SRMNCAH and well-being. While a wide range of studies across country income levels and SRMNCAH priorities were identified, most KT strategies were implemented in highincome countries and focused on maternal, newborn or stillbirths, or child health and well-being topics. The review identified key gaps in KT interventions to support evidence-based decision-making for SRHR, adolescent health and well-being and SRMNCAH financing. Our findings illustrate the majority of KT strategies included an education component and strategies were commonly aimed at addressing healthcare provider and systemlevel outcomes. Across PMNCH outcomes of interest, most strategies address service delivery or policymaking, with none addressing SRMNCAH financing. While few details were typically provided on stakeholder engagement, or on barriers and enablers in the KT process, it was noted that collaboration with stakeholders and building partnerships with local actors, such as government or health authorities, facilitated use of KT strategies.

Low-income and middle-income countries identified a lack of resources (eg, funding, staff, physical resources) as the most common barrier to implementing and sustaining KT strategies. While lack of resources were also identified in high-income countries, these barriers look different based on country income level and are more often pronounced in low-income and middle-income countries. ${ }^{113}$ As we only identified 10 KT strategies implemented or evaluated in low-income countries, this may suggest more work is needed in these countries to move evidence into practice to improve SRMNCAH outcomes, while addressing the economic, resource and health system barriers they experience. ${ }^{115}$ Using a tailored approach to specifically address the unique barriers in low-income countries may help support the successful implementation of KT strategies and improve maternal, child and adolescent health outcomes within these countries. ${ }^{115}$

Engaging with stakeholders was viewed as a key enabler to KT strategies included in this review. Among the groups of stakeholders involved, low-income and middleincome countries were more likely to include members of civil societies and non-governmental organisations compared with high-income countries. Additionally, government and policymakers were engaged by lowincome and middle-income countries much more often than in high-income countries. Involving civil societies in $\mathrm{KT}$, especially among low-income countries, is crucial as these organisations often have the capacity and resources required to implement recommendations. ${ }^{116}$ Drawing on civil society stakeholder groups throughout the design and implementation of KT strategies may provide vital support to help facilitate the implementation and evaluation of KT strategies.

\section{SRMNCAH and well-being}

Maternal health and well-being strategies addressed preterm labour management, labour and delivery outcomes and perinatal care, although primarily in highincome countries. ${ }^{63} 84102103112$ These strategies typically included utilising clinical guidelines and education for nurses to help support improvements in these maternal outcomes. Our review identified a critical gap around effective KT approaches to support evidence-based SRMNCAH interventions in low-income countries. Yet, these women and communities experience more barriers to high-quality healthcare, including trained healthcare providers during childbirth. ${ }^{117} 118$ More investments and capacity strengthening efforts are needed to support KT interventions in low-income settings, thus advancing evidence-based policy and practice in settings where the needs are the most dire. This includes humanitarian and fragile settings, which bear a disproportionate burden 
of poor SRMNCAH outcomes. For instance, maternal mortality increases by $11 \%$ on average in conflict zones and by $28 \%$ in the worst-hit areas. ${ }^{119}$ Additionally, more than 10 million deaths in children younger than 5 years can be attributed to conflict between 1995 and 2015 globally. ${ }^{119}$ In addition, up to a third of girls living in a humanitarian setting report that their first sexual encounter was forced. ${ }^{120}$

Many of the identified strategies were aimed at improving newborn, childhood and maternal mortality rates, particularly in low-income and middle-income countries. 2337525972818690 Strategies included education sessions targeting healthcare providers to ensure quality care is provided to support health outcomes among these groups, and one strategy outlined an advocacy campaign targeting government members to support the provision of free health services for pregnant women and children to help reduce mortality rates. ${ }^{52}$ Providing educational and training opportunities to healthcare providers is vital to targeting health system barriers often experienced in low-income and middle-income countries. ${ }^{18}{ }^{121}$ However, it is recommended to include stakeholder groups within and beyond the health system in these strategies, and these multisectoral stakeholder strategies will need to be sustainable to ensure continuous access to high-quality healthcare for children.

Our review identified an overall lack of relevant KT strategies addressing adolescent health and well-being. This is a significant gap in the literature as adolescents represent over 1.2 billion of today's population, and $90 \%$ of these youth living in low-income and middle-income countries. ${ }^{122} 123$ While the adolescent studies included in this review addressed issues including substance use, mental health and overall health needs, ${ }^{415356} 107$ there is a lack of research into supporting dietary and lifestyle choices and SRHR in this population. Focusing on developing KT programmes and policies to address the health needs of adolescents is essential to supporting the transition into healthy adulthood. Future KT programmes and policies should be codesigned with adolescents and youth to harness their capacity and advocacy skills and to ensure their unique health needs are being addressed. ${ }^{123}$

\section{SRMNCAH financing}

Our review identified a key gap in effective KT interventions to support evidence-based decision-making on SRMNCAH financing. This finding highlights the need for greater efforts to ensure that robust health financing evidence is used to strengthen public financial management systems pertaining to SRMNCAH. ${ }^{124}$ This is critical to support efficient spending in times of COVID-19, whereby governments are struggling with shrinking fiscal spaces and major disruptions to essential SRMNCAH services. ${ }^{125}$

\section{Implications for future KT strategies}

Findings from this scoping review identified educational interventions aimed at changing healthcare provider behaviours to improve provision of care are implemented across all countries and SRMNCAH priorities. Future work should build on these good practices to address issues around SRHR, adolescent health and well-being, and SRMNCAH financing. It will also be essential for teams designing and implementing KT strategies to integrate stakeholder groups early on in the process and codesign KT interventions to optimise the success of work. ${ }^{126}$ Depending on the complexity and scalability of the KT strategies, especially in low-income and middleincome countries, there is an opportunity to identify and address barriers to optimal implementation. Utilising models, such as the Ottawa Model for Research Use recommended by Santesso and Tugwell, throughout the KT process may prove useful to support effective implementation of KT strategies and positive outcomes. ${ }^{115} 127$

Across the studies identified in our review, only $16 \%$ utilised an experimental design, with most studies being observational in nature, thus impeding the assessment of the effectiveness of KT interventions. Future research could benefit from more experimental study designs (eg, cluster randomised control trials, interrupted time series, controlled before and after studies) - and eventually a systematic review and meta-analysis-to evaluate the effectiveness of SRMNCAH strategies, which could provide useful direction and guidance for KT decisionmakers and policymakers.

\section{Limitations}

Due to the rapid nature of this scoping review, it is possible we may have missed relevant KT strategies in the search. Another potential limitation is only identifying one piece of grey literature in the scoping review, which may have been due to our search strategy and strict inclusion criteria. However, our comprehensive literature and grey literature searches identified a broad range of relevant strategies across countries and SRMNCAH priorities. The challenges of identifying relevant $\mathrm{KT}$ strategies and policies may also be due to how varied the terminology is around $\mathrm{KT}$ (eg, KT, knowledge exchange, knowledge mobilisation) and how it is applied across different countries and health areas. ${ }^{128}$ Additionally, while few KT strategies included in the review were implemented and evaluated in low-income countries, this may not reflect all of the KT strategies being implementing across these settings. Although we conducted a search of the grey literature, it is possible publication bias may have impacted our ability to include all unpublished KT work conducted to address SRMNCAH priorities in different settings. ${ }^{129}$ Finally, findings from the review are up to date as of July 2020 and it is possible additional relevant strategies may have been published between running the search strategy and report writing. However, this review provides a comprehensive view of KT strategies which have been published over the past 20 years to address the health and well-being of women, children and adolescents. 


\section{CONCLUSION}

Most KT strategies included in this scoping review were implemented in high-income countries and aimed at maternal, newborn and child health and well-being. We identified a critical gap in the published literature of KT approaches in low-income countries and humanitarian and fragile settings. Meaningful engagement of stakeholders in KT was identified as a key enabler to enhance people-centred and gender-responsive SRMNCAH policy, service delivery and financing. Effective KT approaches are required to support the implementation and impact of multisectoral policies and interventions. As SRMNCAH outcomes worsen as a consequence of the COVID-19 pandemic, it is critical to support SRMNCAH interventions and protect the progress made to date. KT approaches have a key role to play to ensure that strategies to mitigate the disruptions to SRMNCAH services are effective, feasible and acceptable, while addressing the equity gap and ensuring that vulnerable communities are not left behind.

\section{Author affiliations}

${ }^{1}$ School of Nursing, Dalhousie University, Halifax, Nova Scotia, Canada

${ }^{2}$ Pediatrics, IWK Health Centre, Halifax, Nova Scotia, Canada

${ }^{3}$ Faculty of Health, Dalhousie University, Halifax, Nova Scotia, Canada

${ }^{4}$ Department of Community Health and Epidemiology, Dalhousie University, Halifax, Nova Scotia, Canada

${ }^{5}$ Maritime SPOR SUPPORT Unit, Halifax, Nova Scotia, Canada

${ }^{6}$ Nova Scotia Health, Halifax, Nova Scotia, Canada

${ }^{7}$ Centre for Global Child Health, The Hospital for Sick Children, Toronto, Ontario,

Canada

${ }^{8}$ The Partnership for Maternal, Newborn \& Child Health, World Health Organization, Geneva, Switzerland

\section{Twitter Janet A Curran @JCurran_lab and Julia Kontak @juliakontak}

Contributors EVL, ZB, JAC, HW, RU, LB and LW developed the scoping review protocol. JAC, AJG, HDS, JK and EVL contributed to developing the initial draft of the manuscript. All authors provided feedback and revisions to the manuscript. As guarantor for this work, JAC accepts full responsibility for the conduct of the study and has access to the data.

Funding This work was funded by the SPOR Evidence Alliance in collaboration with the Partnership for Maternal, Newborn \& Child Health (PMNCH) at the World Health Organization.

Competing interests None declared.

Patient consent for publication Not applicable.

Ethics approval This study does not involve human participants.

Provenance and peer review Not commissioned; externally peer reviewed.

Data availability statement Data sharing not applicable as no datasets generated and/or analysed for this study.

Supplemental material This content has been supplied by the author(s). It has not been vetted by BMJ Publishing Group Limited (BMJ) and may not have been peer-reviewed. Any opinions or recommendations discussed are solely those of the author(s) and are not endorsed by BMJ. BMJ disclaims all liability and responsibility arising from any reliance placed on the content. Where the content includes any translated material, BMJ does not warrant the accuracy and reliability of the translations (including but not limited to local regulations, clinical guidelines, terminology, drug names and drug dosages), and is not responsible for any error and/or omissions arising from translation and adaptation or otherwise.

Open access This is an open access article distributed in accordance with the Creative Commons Attribution 4.0 Unported (CC BY 4.0) license, which permits others to copy, redistribute, remix, transform and build upon this work for any purpose, provided the original work is properly cited, a link to the licence is given, and indication of whether changes were made. See: https://creativecommons.org/ licenses/by/4.0/.

\section{ORCID iDs}

Janet A Curran http://orcid.org/0000-0001-9977-0467

Allyson J Gallant http://orcid.org/0000-0002-2933-7470

Julia Kontak http://orcid.org/0000-0002-9104-0678

Zulfiqar Bhutta http://orcid.org/0000-0003-0637-599X

\section{REFERENCES}

1 Victora CG, Requejo JH, Barros AJD, et al. Countdown to 2015: a decade of tracking progress for maternal, newborn, and child survival. Lancet 2016;387:2049-59.

2 Protect the progress: rise, refocus and recover. 2020 progress report on the Every Woman Every Child Global Strategy for Women's, Children's and Adolescents' Health (2016-2030) (Licence: CC BY-NC-SA 3.0 IGO). Geneva: World Health Organization and the United Nations Children's Fund (UNICEF), 2020.

3 Moynihan Ret al. Pandemic impacts on healthcare utilisation: a systematic review. medRxiv2020:2020.10.26.20219352.

4 Chmielewska B, Barratt I, Townsend R, et al. Effects of the COVID-19 pandemic on maternal and perinatal outcomes: a systematic review and meta-analysis. Lancet Glob Health 2021;9:e759-72.

5 United Nations Population Fund (UNPFA). Impact of COVID-19 on family planning: what we know one year into the pandemic, 2021. Available: /resources/impact-covid-19-family-planning-what-weknow-one-year-pandemic

6 WHO. Pulse survey on continuity of essential health services during the COVID-19 pandemic: interim report, 2020. Available: https:// www.who.int/publications-detail-redirect/WHO-2019-nCoV-EHS continuity-survey-2020.1 [Accessed 27 Aug 2020].

7 Countdown 2015 Maternal, Newborn \& Child Survival - A Decade of Tracking Progress for Maternal, Newborn and Child Survival: The 2015 Report. Available: http://countdown2030.org/2015/2015-finalreport

8 Organisation for Economic Co-operation and Development. The territorial impact of COVID-19: managing the crisis across levels of government. OECD, 2020. Available: https://www.oecd.org/ coronavirus/policy-responses/theterritorial-impact-of-covid-19managing-the-crisis-across-levels-ofgovernment-d3e314e1/

9 Jha A, Kickbusch I, Taylor P, et al. Accelerating achievement of the sustainable development goals. BMJ 2016;352:i409.

10 The Partnership for Maternal, Newborn and Child Health (PMNCH) PMNCH 2021-2025 strategy, 2021. Available: https://www.who.int/ pmnch/knowledge/publications/pmnch_strategic_plan_2021_2025. pdf?ua $=1$

11 Canadian Institute for Health Research. About knowledge translation, 2016. Available: https://cihr-irsc.gc.ca/e/29418.html\#2

12 Milat AJ, Li B. Narrative review of frameworks for translating research evidence into policy and practice. Public Health Res Pract 2017;27:2711704.

13 Tabak RG, Khoong EC, Chambers DA, et al. Bridging research and practice: models for dissemination and implementation research. Am J Prev Med 2012;43:337-50.

14 Slaughter SE, Zimmermann GL, Nuspl M, et al. Classification schemes for knowledge translation interventions: a practical resource for researchers. BMC Med Res Methodol 2017;17:161.

15 Tricco AC, Lillie E, Zarin W, et al. PRISMA extension for scoping reviews (PRISMA-ScR): checklist and explanation. Ann Intern Med 2018;169:467

16 Peters MDJ, Godfrey CM, Khalil H, et al. Guidance for conducting systematic scoping reviews. Int J Evid Based Healthc 2015;13:141-6.

17 McGowan J, Sampson M, Salzwedel DM, et al. PRESS Peer Review of Electronic Search Strategies: 2015 Guideline Statement. J Clin Epidemiol 2016;75:40-6.

18 Covidence. Covidence systematic review software, veritas health innovation. Melbourne, Australia. www.covidence.org

19 The World Bank. World bank country and lending groups. Available: https://datahelpdesk.worldbank.org/knowledgebase/articles/ 906519-world-bank-country-and-lending-groups

20 Michie S, Atkins L, West R. The behaviour change wheel: a guide to designing interventions. Silverback Publishing, 2014.

21 Michie S, van Stralen MM, West R. The behaviour change wheel: a new method for characterising and designing behaviour change interventions. Implement Sci 2011;6:42. 
22 Page MJ, McKenzie JE, Bossuyt PM, et al. The PRISMA 2020 statement: an updated guideline for reporting systematic reviews. BMJ 2021;372:n71.

23 Abney-Roberts SE. A successful quality improvement project to improve infant safe sleep practice. J Obstet Gynecol Neonatal Nurs 2015;44:S43.

24 Agapidaki E, Souliotis K, Christogiorgos S, et al. A theory-based educational intervention to pediatricians in order to improve identification and referral of maternal depression: a quasiexperimental study. Ann Gen Psychiatry 2013;12:37.

25 Ainsworth RM, Mog C, Summerlin-Long S. A comprehensive newborn falls initiative one year later. J Obstet Gynecol Neonatal Nursing 2014;43:S66

26 Al-Rafay SS, Al-Sharkawy SS. Educational outcomes associated with providing a comprehensive guidelines program about nursing care of preterm neonates receiving total parenteral nutrition. Clin Nurs Res 2012;21:142-58.

27 Alkon A, Crowley AA, Neelon SEB, et al. Nutrition and physical activity randomized control trial in child care centers improves knowledge, policies, and children's body mass index. BMC Public Health 2014;14:215.

28 Allen M, Schafer DJ. Nurses improving the health of mothers and infants by dancing the 10 steps to successful breastfeeding. $J$ Obstet Gynecol Neonatal Nursing 2015;44:S52.

29 Anaby D, Korner-Bitensky N, Law M, et al. Focus on participation for children and youth with disabilities: supporting therapy practice through a guided knowledge translation process. Br J Occup Ther 2015;78:440-9.

30 Ansbro Éimhín M, Gill MM, Reynolds J, et al. Introduction of syphilis point-of-care tests, from pilot study to national programme implementation in Zambia: a qualitative study of healthcare workers' perspectives on testing, training and quality assurance. PLoS One 2015;10:e0127728.

31 Baer VL, Henry E, Lambert DK, et al. Implementing a program to improve compliance with neonatal intensive care unit transfusion guidelines was accompanied by a reduction in transfusion rate: a pre-post analysis within a multihospital health care system. Transfusion 2011;51:264-9.

32 Brennan MM, Fitzpatrick JJ, McNulty SR, et al. Paediatric resuscitation for nurses working in Ghana: an educational intervention. Int Nurs Rev 2013;60:136-43.

33 Cameron D, Russell DJ, Rivard L, et al. Knowledge brokering in children's rehabilitation organizations: perspectives from administrators. J Contin Educ Health Prof 2011;31:28-33.

34 Farner R, Livingston J, Rubio SA, et al. The nurse champion model for advancing newborn screening of critical congenital heart disease. J Obstet Gynecol Neonatal Nurs 2014;43:497-506.

35 Finch M, Wolfenden L, Falkiner M, et al. Impact of a population based intervention to increase the adoption of multiple physical activity practices in centre based childcare services: a quas experimental, effectiveness study. Int J Behav Nutr Phys Act 2012;9:101.

36 Goyet S, Barennes H, Libourel T, et al. Knowledge translation: a case study on pneumonia research and clinical guidelines in a lowincome country. Implement Sci 2014;9:82

37 Hulton L, Matthews Z, Martin-Hilber A, et al. Using evidence to drive action: a "revolution in accountability" to implement quality care for better maternal and newborn health in Africa. Int $J$ Gynaecol Obstet 2014;127:96-101.

38 Jones $\mathrm{COH}$, Wasunna $\mathrm{B}$, Sudoi R, et al. "Even if you know everything you can forget": health worker perceptions of mobile phone text-messaging to improve malaria case-management in Kenya. PLoS One 2012;7:e38636.

39 Kapungu CT, Mensah-Homiah J, Akosah E, et al. A communitybased continuum of care model for the prevention of postpartum hemorrhage in rural Ghana. Int J Gynaecol Obstet 2013;120:156-9.

40 Lang JM, Franks RP, Epstein C, et al. Statewide dissemination of an evidence-based practice using breakthrough series Collaboratives. Child Youth Serv Rev 2015;55:201-9.

41 Mello MJ, Bromberg J, Baird J, et al. Translation of alcohol screening and brief intervention guidelines to pediatric trauma centers. J Trauma Acute Care Surg 2013;75:S301-7.

42 Mody SK, Ba-Thike K, Gaffield ME. The world health OrganizationUnited nations population fund strategic partnership programme's implementation of family planning guidelines and tools in AsiaPacific countries. J Obstet Gynaecol Res 2013;39:825-30.

43 Schreiber J, Marchetti GF, Racicot B, et al. The use of a knowledge translation program to increase use of standardized outcome measures in an outpatient pediatric physical therapy clinic: administrative case report. Phys Ther 2015;95:613-29.
44 Schwartz R, Ellings A, Baisden A, et al. Washington 'Steps' Up: A 10-Step Quality Improvement Initiative to Optimize Breastfeeding Support in Community Health Centers. J Hum Lact 2015;31:651-9.

45 Segre LS, Brock RL, O'Hara MW, et al. Disseminating perinatal depression screening as a public health Initiative: a train-the-trainer approach. Matern Child Health J 2011;15:814-21.

46 Singh K, Speizer I, Handa S, et al. Impact evaluation of a quality improvement intervention on maternal and child health outcomes in northern Ghana: early assessment of a national scale-up project. Int J Qual Health Care 2013;25:477-87.

47 Sobel HL, Mantaring JB, Cuevas F, et al. Implementing a national policy for hepatitis B birth dose vaccination in Philippines: lessons for improved delivery. Vaccine 2011;29:941-5.

48 Sundaram A, Juarez F, Ahiadeke C, et al. The impact of Ghana's R3M programme on the provision of safe abortions and postabortion care. Health Policy Plan 2015;30:1017-31.

49 Tarasoff LA, Epstein R, Green DC, et al. Using interactive theatre to help fertility providers better understand sexual and gender minority patients. Med Humanit 2014;40:135-41.

50 Twum-Danso NA, Dasoberi IN, Amenga-Etego IA, et al. Using quality improvement methods to test and scale up a new national policy on early post-natal care in Ghana. Health Policy Plan 2014;29:622-32.

51 Wolfe AD, Frierdich SA, Wish J, et al. Sharing life-altering information: development of pediatric hospital guidelines and team training. J Palliat Med 2014;17:1011-8.

52 Okonofua F, Lambo E, Okeibunor J, et al. Advocacy for free maternal and child health care in Nigeria--Results and outcomes. Health Policy 2011;99:131-8.

53 Carmona JM, Howe E, Zapata R, et al. 212. The Teen Health Improvement Program: A System-wide Initiative to Improve the Quality of Care for Adolescents Served by the Country's Largest Public Hospital System. Journal of Adolescent Health 2015;56:S108-9.

54 Alvarez E, Lavis JN, Brouwers M, et al. Developing evidence briefs for policy: a qualitative case study comparing the process of using a guidance-contextualization workbook in Peru and Uganda. Health Res Policy Syst 2019;17:89.

55 Barnard JG, Dempsey AF, Brewer SE, et al. Facilitators and barriers to the use of standing orders for vaccination in obstetrics and gynecology settings. Am J Obstet Gynecol 2017;216:69 e1-69.e7.

56 Becker-Haimes EM, Franklin M, Bodie J, et al. Feasibility and acceptability of a toolkit to facilitate clinician use of exposure therapy for youth. Evid Based Pract Child Adolesc Ment Health 2017;2:165-78.

57 Boyko JA, Kothari A, Wathen CN. Moving knowledge about family violence into public health policy and practice: a mixed method study of a deliberative dialogue. Health Res Policy Syst 2016;14:31

58 Braddick L, Tuckey V, Abbas Z, et al. A mixed-methods study of barriers and facilitators to the implementation of postpartum hemorrhage guidelines in Uganda. Int $J$ Gynaecol Obstet 2016:132:89-93.

59 Burgoine K, Ikiror J, Akol S, et al. Staged implementation of a twotiered hospital-based neonatal care package in a resource-limited setting in eastern Uganda. BMJ Glob Health 2018;3:e000586.

60 Close K, Karel M, White M. A pilot program of knowledge translation and implementation for newborn resuscitation using us Peace Corps volunteers in rural Madagascar. Global Health 2016;12:73

61 Edwards N, Kaseje D, Kahwa E, et al. The impact of leadership hubs on the uptake of evidence-informed nursing practices and workplace policies for HIV care: a quasi-experimental study in Jamaica, Kenya, Uganda and South Africa. Implement Sci 2016;11:110.

62 Finch M, Seward K, Wedesweiler T, et al. Challenges of increasing childcare center compliance with nutrition guidelines: a randomized controlled trial of an intervention providing training, written menu feedback, and printed resources. Am J Health Promot 2019;33:399-411.

63 George E, Maloney F, Kara N. Factors determining the utilization of antenatal care in rural and urban settings in Mozambique. Int $J$ Gynecol Obstet 2018;143:523.

64 Gera R, Kapoor N, Haldar P, et al. Implementation of "health systems approach" to improve vaccination at birth in institutional deliveries at public health facilities; experience from six states of India. J Family Med Prim Care 2019;8:1630-6.

65 Gichane MW, Mutesa M, Chowa G. Translating evidence into policy change: advocacy for community-based distribution of injectable contraceptives in Zambia. Glob Soc Welf 2019;6:41-7. 
66 Gilkey MB, Parks MJ, Margolis MA, et al. Implementing evidencebased strategies to improve HPV vaccine delivery. Pediatrics 2019;144:e20182500.

67 Grady A, Wolfenden L, Rissel C, et al. Effectiveness of a dissemination strategy on the uptake of an online menu planning program: a controlled trial. Health Promot J Austr 2019;30 Suppl $1: 20-5$.

68 Guillory C, Gong A, Livingston J, et al. Texas pulse oximetry project: a multicenter educational and quality improvement project for implementation of critical congenital heart disease screening using pulse oximetry. Am J Perinatol 2017;34:856-60.

69 Hardee K, Jurczynska K, Sinai I, et al. Improving voluntary, RightsBased family planning: experience from Nigeria and Uganda. Open Access J Contracept 2019;10:55-67.

70 Kraft JM, Oduyebo T, Jatlaoui TC, et al. Dissemination and use of who family planning guidance and tools: a qualitative assessment. Health Res Policy Syst 2018;16:42.

71 Makkar SR, Howe M, Williamson A, et al. Impact of tailored blogs and content on usage of Web CIPHER - an online platform to help policymakers better engage with evidence from research. Health Res Policy Syst 2016;14:85.

72 Ongolo-Zogo P, Lavis JN, Tomson G, et al. Assessing the influence of knowledge translation platforms on health system policy processes to achieve the health millennium development goals in Cameroon and Uganda: a comparative case study. Health Policy Plan 2018;33:539-54

73 Segre LS, Trusty S, Gullickson R, et al. Brokering the evidencepractice gap: a strategy for moving evidence into clinical practice. Psychiatr Serv 2018;69:852-4.

74 Seward K, Wolfenden L, Finch M, et al. Improving the implementation of nutrition guidelines in childcare centres improves child dietary intake: findings of a randomised trial of an implementation intervention. Public Health Nutr 2018;21:607-17.

75 Uneke CJ, Sombie I, Uro-Chukwu HC, et al. Using equitable impact sensitive tool (EQUIST) to promote implementation of evidence informed policymaking to improve maternal and child health outcomes: a focus on six West African countries. Global Health 2018;14:104

76 Uneke CJ, Sombie I, Uro-Chukwu HC, et al. Using equitable impact sensitive tool (EQUIST) and knowledge translation to promote evidence to policy link in maternal and child health: report of first EQUIST training workshop in Nigeria. Pan Afr Med J 2017;28:37.

77 Vlad I, Paily VP, Sadanandan R, et al. Improving quality for maternal care - a case study from Kerala, India. F1000Res 2016;5:166.

78 Wolfenden L, Nathan N, Janssen LM, et al. Multi-strategic intervention to enhance implementation of healthy canteen policy: a randomised controlled trial. Implement Sci 2017;12:6.

79 Yoong SL, Jones J, Marshall J, et al. A theory-based evaluation of a dissemination intervention to improve childcare cooKs' intentions to implement nutritional guidelines on their menus. Implement Sci 2016;11:105.

80 Kingsnorth S, Orava T, Parker K, et al. From knowledge translation theory to practice: developing an evidence to care hub in a pediatric rehabilitation setting. Disabil Rehabil 2020;42:869-79.

81 Eriksson L, Bergström A, Hoa DTP, et al. Sustainability of knowledge implementation in a low- and middle- income context: experiences from a facilitation project in Vietnam targeting maternal and neonatal health. PLoS One 2017;12:e0182626.

82 Simioni AT, Llanos O, Romero M, et al. [Regionalization of perinatal health care in the province of Santa Fe, Argentina]. Rev Panam Salud Publica 2017;41:e38.

83 Cunningham BJ, Oram Cardy J, Cardy JO. Using implementation science to engage stakeholders and improve outcome measurement in a preschool speech-language service system. Speech Lang Hear 2020;23:17-24.

84 Agency for Healthcare Research and Quality. AHRQ safety program for perinatal care: experiences from the frontline. prepared under contract No. 2902010000241 (RTI international). AHRQ publication No. 17-0003-23-EF. Rockville, MD: Agency for Healthcare Research and Quality, 2016. www.ahrq.gov/perinatalsafety

85 Akter SFU, Heller RD, Smith AJ, et al. Impact of a training intervention on use of antimicrobials in teaching hospitals. J Infect Dev Ctries 2009;3:447-51.

86 Allen CW, Jeffery $\mathrm{H}$. Implementation and evaluation of a neonatal educational program in rural Nepal. J Trop Pediatr 2006;52:218-22.

87 Berglund A, Lefevre-Cholay H, Bacci A, et al. Successful implementation of evidence-based routines in Ukrainian maternities. Acta Obstet Gynecol Scand 2010;89:230-7.

88 Deorari AK, Paul VK, Singh M, et al. Impact of education and training on neonatal resuscitation practices in 14 teaching hospitals in India. Ann Trop Paediatr 2001;21:29-33.
89 Ding $\mathrm{H}$, Yang $\mathrm{Y}$, Wei J, et al. Influencing the use of antibiotics in a Chinese pediatric intensive care unit. Pharm World $\mathrm{Scl}$ 2008;30:787-93.

90 Jeffery HE, Kocova M, Tozija F, et al. The impact of evidence-based education on a perinatal capacity-building initiative in Macedonia. Med Educ 2004;38:435-47.

91 Uskun E, Uskun SB, Uysalgenc M, et al. Effectiveness of a training intervention on immunization to increase knowledge of primary healthcare workers and vaccination coverage rates. Public Health 2008:122:949-58.

92 Warren C, Mwangi A, Oweya E, et al. Safeguarding maternal and newborn health: improving the quality of postnatal care in Kenya. Int J Qual Health Care 2010;22:24-30.

93 Agency for Healthcare Research and Quality. Care transitions from hospital to home: ideal discharge planning implementation Handbook. guide to patient and family engagement, 2017.

94 Alton M, Frush K, Brandon D, et al. Development and implementation of a pediatric patient safety program. Adv Neonatal Care 2006;6:104-11.

95 Brown JJ, Wacogne I, Fleckney S, et al. Achieving early surgery for undescended testes: quality improvement through a multifaceted approach to guideline implementation. Child Care Health Dev 2005;31:119.

96 Carlo WA, Wright LL, Chomba E, et al. Educational impact of the neonatal resuscitation program in low-risk delivery centers in a developing country. J Pediatr 2009;154:504-8.

97 Crone MR, Verlaan M, Willemsen MC, et al. Sustainability of the prevention of passive infant smoking within well-baby clinics. Health Educ Behav 2006;33:178-96.

98 Margolis PA, Stevens R, Bordley WC, et al. From concept to application: the impact of a community-wide intervention to improve the delivery of preventive services to children. Pediatrics 2001;108:E42.

99 Pariyo GW, Gouws E, Bryce J, et al. Improving facility-based care for sick children in Uganda: training is not enough. Health Policy Plan 2005;20 Suppl 1:i58-68.

100 Schreiber J, Stern P, Marchetti G, et al. Strategies to promote evidence-based practice in pediatric physical therapy: a formative evaluation pilot project. Phys Ther 2009;89:918-33.

101 Simmons R, Fajans P, Ghiron L. Chapter 2: Strategic choices in scaling up: introducing injectable contraception and improving quality of care in Viet Nam. In: Scaling up health service delivery: from pilot innovations to policies and programmes. World health Organization, 2007.

102 Goering M, Wilson W. Implementing preterm labor guidelines: a collaborative care improvement process. J Perinat Neonatal Nurs 2002;16:47-57.

103 Davies B, Hodnett E, Hannah M, et al. Fetal health surveillance: a community-wide approach versus a tailored intervention for the implementation of clinical practice guidelines. CMAJ 2002;167:469-74.

104 English KC, Merzel C, Moon-Howard J. Translating public health knowledge into practice: development of a lay health advisor perinatal tobacco cessation program. J Public Health Manag Pract 2010;16:E9-19.

105 Russell DJ, Rivard LM, Walter SD, et al. Using knowledge brokers to facilitate the uptake of pediatric measurement tools into clinical practice: a before-after intervention study. Implement Sci 2010;5:92.

106 Simmons R, Fajans P, Ghiron L. Chapter 7 Scaling up family planning service innovations in Brazil: the influence of politics and decentralization. In: Scaling up health service delivery: from pilot innovations to policies and programmes. World health Organization, 2007.

107 Di Noia J, Schwinn TM, Dastur ZA, et al. The relative efficacy of pamphlets, CD-ROM, and the Internet for disseminating adolescent drug abuse prevention programs: an exploratory study. Prev Med 2003;37:646-53.

108 Dobbins M, Hanna SE, Ciliska D, et al. A randomized controlled trial evaluating the impact of knowledge translation and exchange strategies. Implement Sci 2009;4:61.

109 Melnyk BM, Bullock T, McGrath J, et al. Translating the evidencebased NICU cope program for parents of premature infants into clinical practice: impact on nurses' evidence-based practice and lessons learned. J Perinat Neonatal Nurs 2010;24:74-80.

110 Rowe AK, Onikpo F, Lama M, et al. A multifaceted intervention to improve health worker adherence to integrated management of childhood illness guidelines in Benin. Am J Public Health 2009:99:837-46.

111 Senarath U, Fernando DN, Rodrigo I. Effect of training for care providers on practice of essential newborn care in hospitals in Sri Lanka. J Obstet Gynecol Neonatal Nurs 2007;36:531-41. 
112 Snelgrove-Clarke EE. The effects of action learning on nurses' use of a fetal health surveillance guideline with low-risk labouring women. Available: https://escholarship.mcgill.ca/concern/theses/ dz010q44w

113 Daniels K, Lewin S, Practice Policy Group. Translating research into maternal health care policy: a qualitative case study of the use of evidence in policies for the treatment of eclampsia and preeclampsia in South Africa. Health Res Policy Syst 2008;6:12.

114 Organisation for Economic Co-operation and Development. States of fragility 2020, 2020. Available: https://www.oecd-ilibrary.org/ development/states-of-fragility-2020_ba7c22e7-en

115 Santesso N, Tugwell P. Knowledge translation in developing countries. J Contin Educ Health Prof 2006;26:87-96.

116 Nabyonga Orem J, Marchal B, Mafigiri D, et al. Perspectives on the role of stakeholders in knowledge translation in health policy development in Uganda. BMC Health Serv Res 2013;13:324

117 World Health Organization. Millennium development goals (MDGs), 2018. Available: https://www.who.int/news-room/fact-sheets/detail/ millennium-development-goals-(mdgs)

118 Fenny AP, Crentsil AO, Ackah C. The health MDGs in Ghana: lessons and implications for the implementation of the sustainable development goals. J Public Health 2018;26:225-34

119 Bendavid E, Boerma T, Akseer N, et al. The effects of armed conflict on the health of women and children. Lancet 2021;397:522-32.

120 Stark L, Seff I, Reis C. Gender-based violence against adolescent girls in humanitarian settings: a review of the evidence. Lancet Child Adolesc Health 2021;5:210-22.
121 Oduro-Mensah E, Kwamie A, Antwi E, et al. Care decision making of frontline providers of maternal and newborn health services in the greater Accra region of Ghana. PLoS One 2013;8:e55610.

122 UNICEF. Adolescent health and well-being, 2021. Available: https:// www.unicef.org/health/adolescent-health-and-well-being

123 WHO. Partnership for maternal, newborn and child health. adolescent health and well-being, 2020. Available: http://www.who. int/pmnch/media/news/2019/Adolescent_health_and_well-being_ webinars/en/

124 World Health Organization. WHO | Aligning public financial management and health financing. WHO, 2017. Available: http:// www.who.int/health_financing/documents/aligning-pfm-healthfinancing/en/

125 World Health Organization Regional Office for South-East Asia. Continuing essential sexual reproductive, maternal, neonatal, child and adolescent health services during COVID-19 pandemic 2020.

126 Dal Mas F, Biancuzzi H, Massaro M, et al. Adopting a knowledge translation approach in healthcare co-production. A case study. Management Decision 2020;58:1841-62.

127 Graham ID, Logan J. Innovations in knowledge transfer and continuity of care. Can J Nurs Res 2004;36:89-103.

128 Graham ID, Logan J, Harrison MB, et al. Lost in knowledge translation: time for a MAP? J Contin Educ Health Prof 2006;26:13-24.

129 Rosenthal R. The file drawer problem and tolerance for null results. Psychol Bull 1979;86:638-41. 